\title{
IMPLICATIONS OF NEW ZEALAND'S PRIMARY HEALTH CARE POLICIES FOR MANAGEMENT AND LEADERSHIP
}

\author{
Reuben Olugbenga Ayeleke', Nicola North', Katharine Ann Wallis², Annette Dunham ' \\ 1. Health Systems Section, School of Population Health, the University of Auckland, Auckland, New Zealand \\ 2. Department of General Practice and Primary Health Care, School of Population Health, the University of Auckland, Auckland, \\ New Zealand
}

Correspondence: r.ayeleke@auckland.ac.nz

\begin{abstract}
\section{INTRODUCTION:}

Reforms have been introduced since 2000 to make New Zealand's health system primary care-led. A competent health management workforce is necessary to provide leadership for the goals of the reforms to be realised.
\end{abstract}

\section{AIM AND OBJECTIVE:}

To review New Zealand's key primary health care policies from 2000 to 2016 and consider their implications for management and leadership.

\section{METHODS:}

A document analysis was undertaken using qualitative content analysis. Eligible documents were identified through the websites of relevant government and nongovernment agencies, World Health Organisation, and through Google Scholar.

\section{FINDINGS:}

Two key policy trends relating to primary health care were identified. Firstly, a population health orientation to improve access to health care through community participation, and secondly, an integrated approach to promote collaboration within the health system, and between the health system and other sectors. The inferred management and leadership skillsets required to realise these policies included relationship management and collaboration, change management, and leadership.

\section{CONCLUSION:}

New Zealand's primary health care sector underwent substantial reform between 2000 and 2016. Management and leadership capabilities need to be strengthened and developed for the benefits of the reforms to be realised.

\section{KEYWORDS}

primary health care, management, leadership, policy, competency.

\section{BACKGROUND}

The New Zealand Health Strategy was released in 2000. [1] The key goals included meeting the local needs of the population, promoting access to health care, and eliminating inequalities in health. To achieve these goals, the New Zealand's Primary Health Care (PHC) Strategy was released in 2001 [2] to set the direction for PHC. The intent of the 2001 Strategy was to re-focus the health system away from the hospital to PHC and community, and promote the involvement of local people in the planning and delivery of PHC services at the community level, reflecting the Principles of Primary Health Care set out in the 1978 Alma Ata Declaration. [3]

After a change of government in 2008, further reforms in the health system were aimed at delivering 'better, sooner and more convenient' service, through enhanced coordination and integration of services, and enhanced capability of the PHC sector to undertake ambulatory services generally provided by hospitals. [4] An integrated care approach was expected to result in greater networking, collaboration, and coordination across services. There are 
different types of integration: integration within the PHC sector ('horizontal' integration); integration between primary and secondary health care sectors ('vertical' integration); and integration between the health system and other sectors such as welfare, housing, and employment services ('inter-sectoral' integration). [5] The goal of integrated care is to ensure seamless and continuous care for service users as they move through the health system. The emphasis in New Zealand has been on greater use of primary and community health care services with the aim of shifting care closer to people's homes. [6,7]

These reforms of New Zealand's health system have significantly changed the landscape of its PHC sector, in terms of organisation, ownership, and funding, with farreaching implications for the competencies of those in management and leadership roles. New Zealand's PHC sector is a multi-level and devolved system which at service delivery level comprises general practices with care delivered by general practitioners, nurse practitioners and practice nurses. General practices are members of Primary Health Organisations (PHOs), the next level; PHOs are nongovernment organisations and provide funding for their member general practices to deliver PHC services (some PHOs provide PHC services directly to their enrolled population). The activities of the PHOs are publicly funded through District Health Boards (DHBs), which are responsible for the health needs of the people in their geographical locations, with funding based on the enrolled population i.e. capitation funding. [2]. Finally, there is the Ministry of Health, which exercises monitoring and regulatory power over the DHBs. The PHOs are thus pivotal to the provision of PHC services in New Zealand, especially primary medical care services. Though funding of PHOs is based on the enrolled population, enrolment by patients in a $\mathrm{PHO}$ is voluntary, with most New Zealanders enrolled through their general practices. In effect, the New Zealand PHC sector is a hybrid system where private and public institutions collaborate to deliver PHC services.

Strong management and leadership workforces have been recognised as crucial for driving changes and implementing reforms in the healthcare sector. [8.9] However, the competencies required in effectively managing and leading health services is a neglected area in New Zealand. [10] To date, there is a lack of consensus on competency frameworks against which to assess the competence of the New Zealand health management and leadership workforce, particularly in primary health care. In contrast, the Health Practitioners Competence
Assurance (HPCA) Act [11] requires that the competence of regulated health professions is specified, and practitioners must demonstrate their competence against standards. However, the HPCA Act does not cover nonclinical health managers, for whom there are no equivalent high-level competence standards to provide guidance to service providers. Thus, little is known about the New Zealand health management and leadership workforce, in terms of its managerial effectiveness, specific competencies, and training requirements. Given the absence of such information, a starting point to an understanding of what these competencies might be is to analyse documents setting out policy and strategic direction for the PHC sector. Such an understanding will facilitate the identification of requisite competencies to inform appropriate training and professional development, and to subsequently improve competence and performance in roles.

\section{AIM}

The study aimed to identify and review key national-level strategies and policies on New Zealand's PHC and consider their implications for management and leadership competencies

\section{METHODS}

This is a document analysis which involved qualitative content analysis. Documents eligible for analysis were those announcing or outlining key government policies or intended policies on New Zealand's PHC. Also eligible for analysis were evaluation reports or commentary on specific policy that had implications for management and leadership competencies. Excluded were documents that analysed, evaluated, or reviewed policies or strategies that had no implications for management and leadership competencies at the national level. Both published and unpublished documents available from 2000 to 2016, that is, documents available since the release of the New Zealand Health Strategy in 2000 and the updated version of the Strategy in 2016, were included. This timeframe coincides with a period when New Zealand's health system underwent significant re-orientation towards a PHC-led system.

\section{SEARCH METHODS FOR DOCUMENTS}

A comprehensive search was undertaken to identify relevant documents. The websites of the following New Zealand agencies and organisations were searched to 30 September 2017: Ministry of Health, District Health Boards, 
Primary Health Organisations, College of General Practitioners, New Zealand Parliament, National and Labour political parties and newspaper archives. We also searched the website of the World Health Organisation, and Google Scholar electronic database using the subject heading 'New Zealand primary health care' as the search strategy. Other resources included hand searching of reference lists of included and excluded documents.

\section{SELECTION AND EVALUATION OF DOCUMENTS}

All potentially eligible documents were retrieved in full text and checked for compliance with the inclusion criteria. The selected documents were assessed for authenticity, credibility, representativeness and meaning. [12,13] The above process was facilitated by two authors (ROA and $\mathrm{NN}$ ) with any disagreement resolved through discussions.

\section{ANALYSIS \\ Documents were analysed using qualitative content analysis involving inductive thematic analysis. [12.14] The selected documents were read to identify sentences, terms, and quotes pertinent to the study aim and objectives. Where the competencies required to deliver the strategies were not explicit in the documents, we continued the analysis with an interpretative lens to identify implications of policies and strategies for competencies relevant at the national level.}

Coding was performed by identifying words, terms, or phrases in the selected data relevant to policy directions and/or implications for management and leadership competencies, with codes summarised on a spreadsheet. Using a constant comparative process, new codes identified in a new data set were then applied to the already coded data sets to ensure the new codes were not omitted. Similar codes were organised into substantive categories and compared across documents and data sets to identify similarities, differences, and emerging patterns. Categories that were similar in meaning were organised into themes or sub-themes which were examined to see how they related to policy trends or the implications of those policies for management and leadership competencies.

\section{RESULTS}

\section{RESULTS OF THE SEARCH}

A total of 56 documents were identified after removal of duplicates. Of these, 23 documents, either proposing, setting out or critiquing policy, met the eligibility criteria for inclusion. Table 1 below summarises the characteristics of documents included in analysis.

\section{ASSESSMENT OF THE QUALITY OF DOCUMENTS}

Documents were evaluated for authenticity, credibility, representativeness and meaning. Included documents were assessed as: genuine and reliable; having been authored by organisations or individuals of unquestioned credentials; containing information emanating either from authors' first-hand experience or from verifiable sources; and as representative of policy documents on New Zealand's PHC. None of the documents were considered comprehensive in terms of providing broad and wide coverage of the key policy directions, as they individually addressed a specific policy direction at a point in time. Importantly for this analysis, the included documents did not explicitly address the competencies required by the management workforce to implement the strategies.

\section{IDENTIFIED POLICY TRENDS}

Two key policy trends were identified, reflecting the periods in which the two major political parties were in government and the policies they introduced.

1. Documents published from 2000 to 2007 (Labourled government)

2. Documents published after 2007 to 2016

(conservative National-led government)

\section{POPULATION ORIENTED PRIMARY HEALTH CARE: 2000 - 2007}

The evolution of population oriented PHC was the substantive policy direction identified from the analysis of documents released between 2000 and 2007. [1,2,15-20] Three main subthemes emerged from the coding process:

1. Improving the health of the population through the establishment of community-based Primary Health Organisations to coordinate primary health care services

2. Improving access to PHC

3. Improving the coordination of car 
TABLE 1 CHARACTERISTICS OF DOCUMENTS INCLUDED IN ANALYSIS

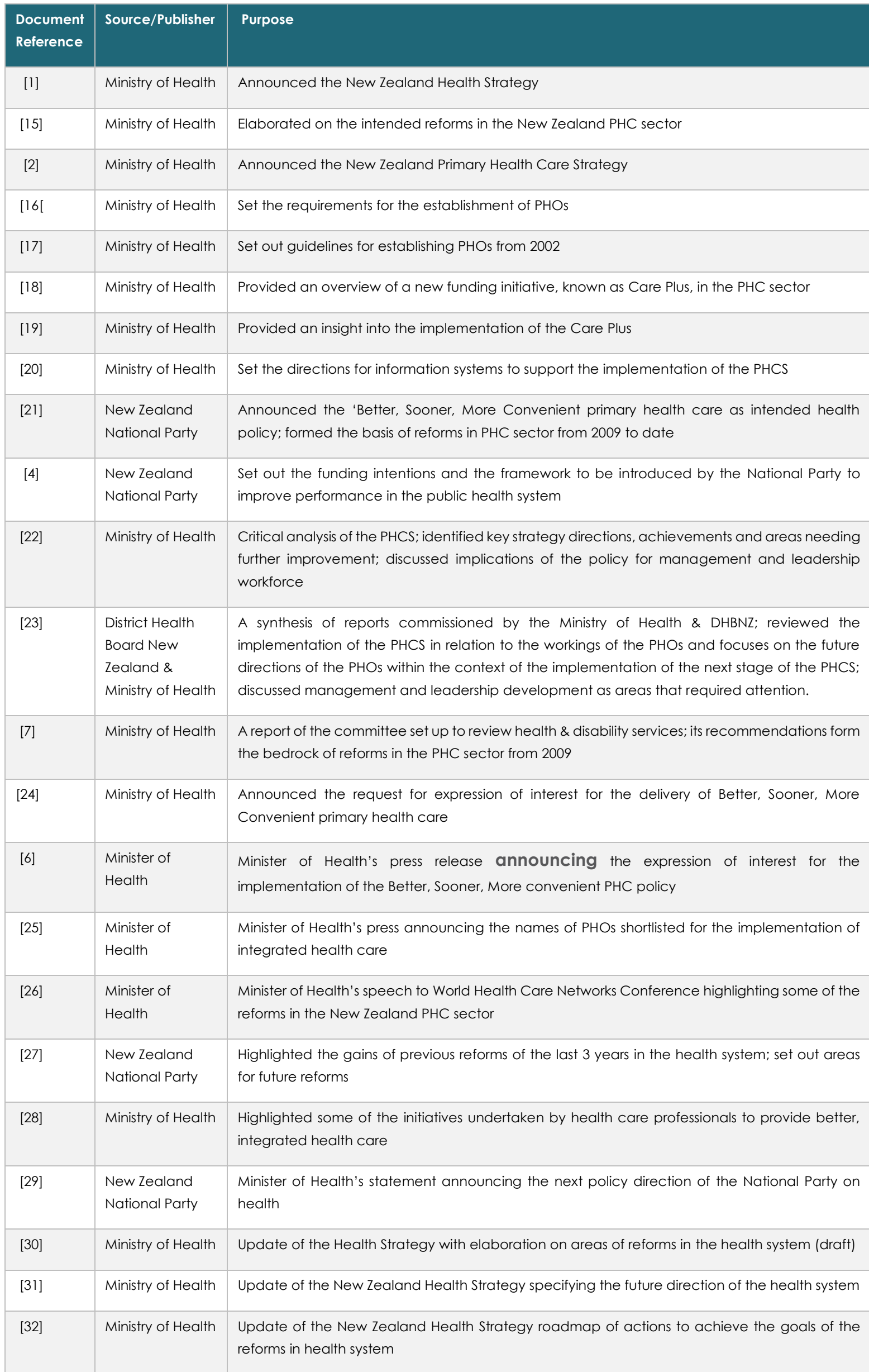


POLICY IMPLICATIONS FOR HEALTH MANAGEMENT

\section{AND LEADERSHIP COMPETENCIES}

The implications for management and leadership competencies were not explicit in the documents included in the analysis. However, those competencies were alluded to, identified through a semiotic analysis of some of the documents. Three themes emerged on the implications of the two policy trends for management and leadership competencies:
1. Relationship management and collaboration skills

2. Change management skills

3. Leadership skills

Codes reflecting these competencies are summarised in Table 2 below.

\section{TABLE 2 IDENTIFIED CODES FOR MANAGEMENT AND LEADERSHIP COMPETENCIES}

\begin{tabular}{|l|l|}
\hline THEMES & KEY CODES \\
\hline $\begin{array}{l}\text { 1. Relationship } \\
\text { management } \\
\text { and } \\
\text { collaboration }\end{array}$ & $\begin{array}{l}\text { *elationship management, *management of relationships, *develop services in a } \\
\text { collaborative manner, *focus on collaborative planning, *enable a more extensive } \\
\text { and better co-ordinated range of services }\end{array}$ \\
\hline $\begin{array}{l}\text { 2. Change } \\
\text { management }\end{array}$ & $\begin{array}{l}\text { *management approach that might enable the achievement of these ambitious } \\
\text { objectives, *encourages reflection on current working practices, *allows the } \\
\text { development of a set of shared desired outcomes for local service change, }\end{array}$ \\
\hline 3. Leadership & $\begin{array}{l}\text { *implementation of change to patient services within primary care, *reshape } \\
\text { services, *quality improvement, *management of change }\end{array}$ \\
& $\begin{array}{l}\text { *tronger cross-sector engagement and leadership, *stronger collective leadership } \\
\text { clinicians and managers, *greater clinical leadership, *medical leadership, } \\
\text { *combined clinical and managerial leadership across the sector }\end{array}$ \\
\hline
\end{tabular}

\section{DISCUSSION}

Major structural changes to the organisation, funding, and delivery of $\mathrm{PHC}$ services have arisen from the reforms in New Zealand's PHC sector between 2000 and 2016.. The population oriented PHC policy, which was the main focus of the reforms undertaken between 2000 and 2007, makes the health and wellbeing of the people the core of services within the PHC sector. Services hitherto provided by individual general practices were brought under the coordination of a new set of organisations, i.e. the PHOs. This policy encourages active participation of communities in the governance of PHOs and delivery of PHC services through their involvement in identifying health needs, design, and implementation of appropriate approaches to solving identified health issues. The policy also emphasises the need for multi-disciplinary approaches to decision making among health care professionals. The main objective of this policy is to reduce health inequalities and improve access to PHC services by reducing major barriers to access. Changes were made to government subsidies and funding systems, with the fees-for-service model of payment complemented with capitation funding, based on population needs and enrolled population to reduce patient co-payment.

The main thrust of the reforms undertaken from 2007 to 2016 was geared towards integration of care within and between primary and secondary care on one hand, and between the health system and other sectors on the other. These reforms were informed by the perceived shortcomings inherent in the implementation of the PHC Strategy. These shortcomings included rising spending on 
health services, concern for patient safety and quality of services and inequalities in service improvement such as long waiting times and access to certain specialist services. [7] As a way forward, the New Zealand National Party, then in opposition, in 2007 proposed a major policy direction through the 'Better, Sooner, and More Convenient' document. [21] This document forms the basis of the government policy on PHC from 2007 to 2016. The integrated healthcare policy aimed to promote safe, effective and efficient health services within the shortest possible time and with less discomfort to patients. [4,6] Of interest was the recognition of the need for clinicians to be more actively involved in the planning of health services through the concept of clinical leadership. [7] This, in effect, was expected to set the pace for stronger collaboration between clinicians as clinical leaders, and other professionals in management or leadership roles. Thus, the hitherto 'managerialism' structure, dominated by generalist trained managers, was expected to give way to a unified collective leadership structure. Such a unified leadership structure requires health care organisations to develop individuals and teams to work collaboratively for the greater good of the populations. [33]

The changes anticipated by the reforms in New Zealand's PHC sector are complex and far-reaching; the process of managing these changes and dealing with the attendant consequences (both intended and unintended), require a high level of management and leadership competence. [22] For example, integrated care requires management and leadership structures with the capacity to stimulate stakeholders to work in a more collaborative manner across all levels of the PHC system, where relationships have been described as 'massively entangled', [34] and between the $\mathrm{PHC}$ and other sectors of the health system. This point was also emphasised in the report of the Health Workforce Advisory Committee in making the case for strong leadership at different levels of the PHC sector for successful implementation of the PHC Strategy. [35] In his exploratory study, Love also noted that:

Issues of leadership and management tend to be more important to the success of a practice ...In many cases changes in service delivery had been the result of strong leadership from individuals in practice. [36, p. 1]

Other authors have also stressed the importance of management and leadership in driving innovations in the PHC sector. [37-40] The hybrid nature of New Zealand's PHC system will no doubt pose a daunting challenge for the implementation of high-level strategies such as those related to the development of management and leadership capabilities. This is particularly so given the limited direct influence policy makers have on private organisations. Nonetheless, such complexity should not obviate the need for clear strategy directions to guide implementation of initiatives to strengthen the capabilities of management and leadership personnel. While individual organisations (such as PHOs and DHBs) may have embarked on initiatives to strengthen the capabilities of their management and leadership personnel, the effectiveness of such measures remains unclear, particularly when little is currently known about the specific competencies required by the New Zealand health management and leadership workforces. The development of a competency framework for the PHC management and leadership workforces will assist in strengthening their capabilities. Such a framework is used to assess performance, identify gaps in proficiency and target appropriate training and professional development. [41]

Only three skill sets related to the implementation of some of the reforms were inferred from (but not explicit in) the policy and strategy documents. These were: 1) relationship building and collaboration skills; 2) change management skills; and 3) leadership skills. The absence in policy documents of the implications of reforms for management and leadership competencies underlines the scant attention paid to the capabilities of health managers and leaders in New Zealand's PHC sector at the national level. Indeed, it reflects a taken-for-granted view, without the evidence to support it, that such capabilities exist.

In view of inadequate information and lack of clarity on what competencies are required by the management and leadership of PHC in New Zealand in documents analysed, research conducted elsewhere was considered to identify competencies potentially applicable to New Zealand's $\mathrm{PHC}$ sector. One such study is the Managerial Competency Assessment (MCAP) study conducted by Liang and colleagues [42] among community health services managers in Victoria, Australia. The Liang et al study was selected because of some similarities in context between the Australian and New Zealand health systems, community health services in Australia being equivalent of PHOs in New Zealand. The study identified seven competencies considered essential for senior and middle level managers in community health services. These were: evidence-informed decision-making; interpersonal, 
communication qualities and relationship management; knowledge of the health care environment and the organisation; operations, administration, and resource management; leading and managing change; leadership; and professionalism. [42] Three of these competencies (interpersonal, communication qualities and relationship management; leading and managing change; and leadership) are identical to the competencies inferred from our analysis of documents as essential for management and leadership of the reforms in New Zealand's PHC sector (i.e. relationship management and collaboration, change management, and leadership skills). While it is possible that the remaining competencies identified by Liang and colleagues are applicable to the New Zealand PHC context, reflecting the notion of core competencies, [43] their applicability is worth testing in the New Zealand health system given its particular characteristics.

\section{CONCLUSIONS}

In the past two decades there has been substantial reform of the New Zealand health sector, resulting in a PHC-led health system. A critical review of the policy documents on New Zealand's PHC revealed limited recognition of the management and leadership competencies needed to implement major reforms, and a subsequent lack of guidance at the national level on how to develop the capabilities of the management and leadership workforce. If the goals of the policies are to be realised, management and leadership capabilities across all levels of $\mathrm{New}$ Zealand's PHC sector and its interface with other health and social sectors will need to be developed and strengthened. While individual organisations in the PHC sector may be investing in initiatives to strengthen the capabilities of their management and leadership personnel, the effectiveness of those measures remains unclear in the absence of clear strategy directions to guide implementation of management development. The absence of formal competency frameworks against which to assess competencies and identify gaps in proficiencies may further limit the effectiveness of any efforts to strengthen management and leadership capabilities in New Zealand's PHC sector. A starting point will be the identification of competencies required by the management and leadership workforces in New Zealand's PHC sector to inform the development of appropriate training and professional development interventions.

\section{Reference}

[1] Ministry of Health. The New Zealand Health Strategy. Wellington: Ministry of Health; 2000a. Available: http://www.moh.govt.nz (Assessed $31 / 08 / 16)$.

[2] Ministry of Health. The Primary Health Care Strategy. Wellington: Ministry of Health; 2001 a. Available: http://www.moh.govt.nz (Assessed 18/09/16).

[3] World Health Organisation. Alma-Ata1978 Primary health care: Report of the International Conference on Primary Health Care, Alma-Ata, USSR, 6-12 September 1978. Geneva: World Health Organization; 1978. Report No.: CF/HST/1985-034/Anx.04/07.

[4] New Zealand National Party. Health policy part 1: funding and framework [internet]. Wellington: New Zealand National Party; c2008-09. Available: https://www.national.org.nz/health (Assessed 29/08/16).

[5] Cumming J. Integrated Care in New Zealand. Int J Integr Care 2011;11(5):1-13.

[6] Ryall T. Government takes primary health care forward [internet]. Wellington: Minister of Health; c2009a. Available:

https://www.beehive.govt.nz/release/govt-takesprimary-health-care-forward (Assessed 03/12/15).

[7] Ministerial Review Group. Meeting the Challenge: Enhancing Sustainability and the Patient and Consumer Experience within the Current Legislative Framework for Health and Disability Services in New Zealand. Wellington: Ministerial Review Group; 2009. Available: http://www.moh.govt.nz (Assessed 23/12/15).

[8] Jones L, Torney L, Baxter S, Dudley R, Johnson D, $O$ 'Brien $A$, et al. Developing healthcare leaders for the 21 st century: understanding and maximising leadership in pre-registration healthcare curricula in the West Midlands, UK. Physiotherapy 2015;101:e691e692.

[9] Leigh J, Wild J, Hynes C, Wells S, Kurien A, Rutherford J, et al. Transforming community services through the use of a multidimensional model of clinical leadership. J Clin Nurs 2015;24(5-6):749-760.

[10] North N, Park E. Potential for a web-based tool to confirm and update health management and leadership competencies. Experiences of a pilot 
survey in New Zealand. Asia Pacific Journal of Health Management 2014;9(2):13-20.

[1 1] Ministry of Health. The Health Practitioners Competence Assurance Act. Wellington: Ministry of Health; 2003. Available: https://www.health.govt (Assessed 30/08/16)

[12] Bowen GA. Document analysis as a qualitative research method. Qualitative Research Journal 2009:9(2):27-40.

[13] Berger AA. Media analysis techniques. 5th ed. Newbury Park: Sage Publications; 2013.

[14] Fereday J, Muir-Cochrane E. Demonstrating rigor using thematic analysis: A hybrid approach of inductive and deductive coding and theme development. Int J Qual Methods 2006;5(1):80-92.

[15] Ministry of Health. The future shape of primary health care. Wellington: Ministry of Health; 2000b. Available: http://www.moh.govt.nz/primarycare.html (Assessed 23/11/2015).

[16] Ministry of Health. Primary Health Care Strategy: Minimum Requirements for Primary Health Organisations. Wellington: Ministry of Health; $2001 \mathrm{~b}$. Available: http://www.moh.govt.nz (Assessed 16/09/16).

[17] Ministry of Health. A Guide for Establishing Primary Health Organisations. Wellington: Ministry of Health; 2002. Available: http://www.moh.govt.nz (Assessed 16/03/16).

[18] Ministry of Health. Care Plus; an Overview. Wellington: Ministry of Health; 2004. Available: http://www.govt.nz (Assessed 26/04/16).

[19] Ministry of Health. Review of the Implementation of Care Plus. Wellington: Ministry of Health; 2006.

Available: http://www.moh.govt.nz (Assessed 22/12/15).

[20] Ministry of Health. Primary Health Care Strategy: Key directions for the information environment. Wellington: Ministry of Health; 2007. Available: http://www.moh.govt.nz (Assessed 19/12/15)

[21] Ryall T. Better, Sooner, More convenient. Wellington: New Zealand National Party; 2007. Available: http://www.national.org.nz (Assessed 12/02/16)

[22] Smith J. Critical analysis of the implementation of the Primary Health Care Strategy implementation and framing of issues for the next phase. Wellington: Ministry of Health; 2009.

[23] Smith J, Cumming J. Where Next for Primary Health Organisations in New Zealand? Wellington: Health Services Research Council, Victoria University of Wellington; 2009. Available: http://www.health.govt.nz (Assessed 26/01/16).

[24] Ministry of Health. Request for Expression of Interest (EOI) for the Delivery of Better, Sooner, More Convenient Primary Health Care. Wellington: Ministry of Health; 2009 [cited 2016 Jan 25]. Available: http://www.moh.govt.nz (Assessed 25/01/16).

[25] Ryall T. Nine short listed for next steps in primary care [internet]. Wellington: Minister of Health; c2009b. Available:

http://www.beehive.govt.nz/release/nine+short+listed +next+steps+primary+care (Assessed 09/03/17).

[26] Ryall T. Health Minister's speech to world health care networks conference [internet]. Auckland: World Health Care Networks Conference; 22 July 2010. Available:

https://www.beehive.govt.nz/speech/healthminister039s-speech-world-health-care-networksconference. (Assessed 09/03/17).

[27] New Zealand National Party. Health: shorter waiting times. Building better public services. Wellington: New Zealand National Party; 2011. Available: http://www.national.org.nz (Assessed 23/12/15).

[28] Ministry of Health. Care Closer to Home. Wellington: Ministry of Health; 2014. Available: http://www.moh.govt.nz (Assessed 17/11/16).

[29] Ryall T. National Party: Making New Zealand the best place in the world to grow up and grow old. N Z Med J 2014;127(1401):17-21.

[30] Ministry of Health. Update of the New Zealand Health Strategy: All New Zealanders live well, stay well, get well: Consultation draft. Wellington: Ministry of Health; 2015. Available: http://www.moh.govt.nz (Assessed 18/12/16).

[31] Ministry of Health. New Zealand Health Strategy: Future direction. Wellington: Ministry of Health; 2016 a. Available: http://www.moh.govt.nz (Assessed 04/10/2017).

[32] Ministry of Health. New Zealand Health Strategy: Roadmap of actions. Wellington: Ministry of Health; 
2016b. Available: http://www.moh.govt.nz (Assessed 04/10/17).

[33] West MA, Eckert R, Steward K, Pasmore WA.

Developing collective leadership for health care. London: King's Fund; 2014. Available:

http://www.kingsfund.org.uk (Assessed 15/12/18).

[34] Sibthorpe B, Glasgow N, Longstaff D. Complex adaptive systems: a different way of thinking about health care systems [internet]. Canberra: Australian Primary Health Care Research Institute; c2004. Available: http://www.betterevaluation.org/ (Assessed 24/11/16).

[35] Health Workforce Advisory Committee. The New Zealand Health Workforce Future Directions Recommendations to the Minister of Health. Wellington: Health Workforce Advisory Committee; 2003. Available: http://www.moh.govt.nz (Assessed 22/04/15).

[36] Love T. Evolution in Practice, Aspects of Change and Development in New Zealand Primary Health Care. Wellington: District Health Boards New Zealand and Ministry of Health; 2008.

[37] McDonald J, Cumming J, Haris M, Davis G, Burns $P$. Systematic review of system-wide models of comprehensive primary health care. Melbourne: Research Centre for Primary Health Care and Equity, UNSW; 2006.

[38] Goodwin N, Smith J. The evidence base for integrated care. London: King's Fund and the Nuffield Trust; 2011.

[39] Rosen R, Mountford J, Lewis G, Lewis R, Shand J, Shaw S. Integration in action: four international case studies. London: Nuffield Trust; 2011.

[40] Ramsay A, Fulop N. The evidence base for integrated care. London: Department of Health; 2008.

[41] Ayeleke RO, Dunham A, North N, Wallis K. The Concept of Leadership in the Health Care Sector. In: S.

D. Goker (Ed.) Leadership (pp. 83-95). London: Intechopen; 2018. 10.5772/intechopen.76133.

[42] Liang Z, Howard PF, Koh LC, Leggat S. Competency requirements for middle and senior managers in community health services. Aust J Prim Health 2013;19(3):256-263.

[43] Calhoun JG, Dollett L, Sinioris ME, Wainio JA, Butler PW, Griffith JR, et al. Development of an interprofessional competency model for healthcare leadership. Journal of Healthcare Management 2008;53(6):375. 